\title{
Bycatch and discard mortality in commercially caught blue sharks Prionace glauca assessed using archival satellite pop-up tags
}

\author{
Steven E. Campana ${ }^{1, *}$, Warren Joyce ${ }^{1}$, Michael J. Manning ${ }^{2,3}$ \\ ${ }^{1}$ Bedford Institute of Oceanography, PO Box 1006, Dartmouth, Nova Scotia, Canada B2Y 4A2 \\ ${ }^{2}$ National Institute of Water and Atmospheric Research Ltd (NIWA), Private Bag 14901, Kilbirnie, Wellington, New Zealand \\ ${ }^{3}$ Oceanic Fisheries Programme, Secretariat of the Pacific Community (SPC), BP D5, 98848 Noumea Cedex, New Caledonia
}

\begin{abstract}
Blue sharks Prionace glauca are the most frequently discarded fish species during commercial pelagic longline fishing operations worldwide, yet their post-release mortality rate has never been measured. A generalized linear model of 12404 blue sharks observed during the Canadian Atlantic pelagic longline swordfishery suggested a hooking mortality of 12 to $13 \%$, yet scientific examination of 902 of these sharks indicated that hooking mortality was actually higher. A random sample of 40 of these blue sharks were tagged with satellite pop-up archival transmission (PAT) tags, then monitored for periods of up to 6 mo after release. All of the surviving sharks exhibited a depthholding recovery behaviour for a period of 2 to $7 \mathrm{~d}$ after release. All healthy sharks survived, while $33 \%$ of those that were badly injured or gut hooked subsequently died. Overall blue shark bycatch mortality in the pelagic longline fishery was estimated at $35 \%$, while the estimated discard mortality for sharks that were released alive was $19 \%$. Survival time models indicated that $95 \%$ of the mortality occurred within $11 \mathrm{~d}$ of release, indicative of death by trauma rather than starvation. The annual blue shark catch in the North Atlantic was estimated at about $84000 \mathrm{t}$, of which $57000 \mathrm{t}$ is discarded. A preliminary estimate of $20000 \mathrm{t}$ of annual dead discards for North Atlantic blue sharks is similar to that of the reported nominal catch, and could substantially change the perception of population health if incorporated into a population-level stock assessment.
\end{abstract}

KEY WORDS: Discard mortality $\cdot$ Hooking mortality $\cdot$ Tagging $\cdot$ Bycatch $\cdot$ Satellite tags Resale or republication not permitted without written consent of the publisher

\section{INTRODUCTION}

Fishing methods are often non-selective with respect to the species captured, resulting in the capture of both the target and non-target species. Where the nontarget species is considered commercially valuable, bycatch is usually retained and can thus be accounted for in a population status assessment. However, bycatch of non-commercial, unretained species can lead to their injury or death, and may be driving population declines of many species on a global scale (Lewison et al. 2004). Marine megafauna such as sea turtles, seabirds, sharks and marine mammals appear to be particularly susceptible to bycatch mortality in fishing gear. However bycatch and discarding of less charismatic species is also viewed as a global problem (Har- rington et al. 2005). The magnitude of the bycatch issue was examined by Harrington et al. (2005), who reported that more than one million tons of fish (equal to $28 \%$ of landings) were discarded annually in US waters alone. Global discards have never been quantified, but presumably are much larger in quantity.

Bycatch mortality can be categorized into capture mortality (e.g. immediate or hooking mortality) and post-release (or discard) mortality. Capture mortality is readily quantified, since it can be assessed on board the fishing vessel at the time the fishing gear is pulled aboard. However, the assessment of post-release mortality is more problematic. Unpredictable and potentially large discard mortality rates can result from injuries due to fishing and handling, as well as the stress of capture plus the complicating effects of envi- 
ronmental conditions at the time of release (Davis 2002). The difficulty in quantifying post-release mortality is due to the scarcity and/or expense of methods for tracking released fish in the wild over periods of time of up to several months. Most studies have attempted to avoid this issue by holding fish in cages or pens for several days after capture (e.g. Neilson et al. 1989). However, holding pens provide a clearly artificial and spatially constrained environment, and thus have the potential to introduce (or avoid) sources of mortality that would not be present under natural, free-swimming conditions. As a result, some sort of tag-recapture or telemetry program is required to properly estimate the post-release mortality rate of discarded fish (Davis 2002, Pollock \& Pine 2007, Skomal 2007). Such a program would be well suited for monitoring released fish in the wild for extended periods of time, and has been successfully applied in estimating short-term discard mortality rates in large pelagic fish such as striped marlin (Tetrapturus audax) (Domeier et al. 2003). An additional advantage of such studies is that evidence of physical trauma or stress indicators from blood chemistry can ultimately be linked to the subsequent survival rate, thus providing predictors for discard mortality rate.

Sharks are often the most frequently discarded category in longline fisheries for highly migratory pelagic species such as tuna and swordfish (Lewison et al. 2004, Harrington et al. 2005), and blue sharks Prionace glauca are often the most abundant of these shark species. Bonfil (1994) estimated that 6.2 to 6.5 million blue sharks were taken annually by high seas fisheries globally, which would rank them amongst the most numerous species in the large pelagic catch category. Blue shark accounted for almost half the catch in New Zealand tuna fisheries (Francis et al. 2001), up to $34 \%$ of the large pelagic catch in certain areas of the Mediterranean (Megalofonou et al. 2005), and was among the 3 most frequently caught species in the tuna and swordfish fisheries of the Pacific Ocean (Ward et al. 2004). In the northwest Atlantic, blue sharks accounted for an average of $34 \%$ of the total catch weight in Canadian large pelagic fisheries (Campana et al. 2006), about $10 \%$ of the total catch weight in US fall fisheries for tuna and swordfish (Kerstetter \& Graves 2006), and about $59 \%$ of the catch in Japanese tuna longline fisheries (Matsunaga \& Nakano 2000). Due to low commercial value in many countries, most of these blue sharks were discarded at sea. However, the fate of these discarded sharks has never been quantified. Capture mortality rates of 5 to $31 \%$ (Francis et al. 2001, Diaz \& Serafy 2005, Megalofonou et al. 2005) indicate that overall discard mortality could be substantial. Indeed, based on estimates of overall blue shark catch in the North Atlantic (Campana et al.
2006), it is possible that dead discards account for greater blue shark fishing mortality than do reported landings. As first mentioned by Bonfil (1994), the absence of discard mortality estimates seriously compromises attempts at providing credible stock assessments for North Atlantic blue sharks.

Post-release mortality rate has not yet been estimated for a pelagic shark species, despite observations from several studies that archival satellite pop-up tags would be ideal for this purpose (Davis 2002, Pollock \& Pine 2007, Skomal 2007). We hypothesized that the typically unobserved post-release mortality rate of blue sharks would be of comparable magnitude to that of the more readily observed capture mortality, and that the probability of mortality would increase with the severity of injury. Therefore, the objectives of the current study were 4-fold: (1) to use extensive observer data on Canadian pelagic longliners to estimate hooking mortality of blue sharks; (2) to test the value of archival satellite pop-up tags as indicators of postrelease mortality in discarded blue sharks; (3) to estimate post-release mortality rate in discarded commercially-caught blue sharks according to severity of injury; and (4) to infer the implications of discard mortality rates on overall fishing mortality of blue sharks in the North Atlantic.

\section{MATERIALS AND METHODS}

The factors affecting the hooking mortality of blue sharks captured as part of commercial longline fishing for swordfish Xiphias gladius were analyzed using data collected by the Scotia-Fundy Observer Program (SFOP). The observed fishing sets were from observations made by Canadian pelagic longliners targeting swordfish in the northwest Atlantic. A total of 513 sets made between May and December in the years 2001 to 2008 were included in the analysis. The variables recorded by the observers included hook type and size, vessel identity, location fished, date, soak time (= set duration), surface water temperature, and the total number of blue sharks caught. As each shark was pulled up to the rail, its status as healthy, injured or dead was recorded, along with an estimate of its length. Most sharks were removed from the hook (or had the gangion cut without first removing the hook) without being brought aboard, and could not be closely examined, thus making the status classification somewhat uncertain. The status of $1.6 \%$ of the blue sharks could not be determined, largely because it was unclear if the shark was actually dead as opposed to unmoving. These sharks were removed from the analysis. Some observers were apparently unaware of the requirement to record the incidence of dead 
sharks, and never reported dead sharks on any trip; therefore, those trips which reported no dead blue sharks were excluded from the analysis, leaving a sample size of 12404 sharks. Since the observers did not use a standardized distinction between healthy and injured sharks, the analysis was restricted to the proportion dead upon retrieval of the gear.

The hooking mortality data from the Observer Program was analyzed using a generalized linear model (GLM) with a binomial response (alive vs. dead). The main effects included in the model were hook type, hook size, soaktime, vessel identity, surface water temperature and fork length. The interaction between hook type and hook size was also included. The analysis was carried out in S-PLUS 7.0 (Tibco, www. insightful.com).

A more detailed dataset of blue shark injury and mortality status was obtained by scientific staff working on board commercial fishing boats between 2003 and 2007. The fishing vessels were typical of Canadian pelagic longliners fishing for swordfish (and in one case, blue sharks) in the fall fishery, but more trips would need to be monitored to be fully representative of the fishery. Although we cannot rule out the possibility that the crew treated the blue shark bycatch more gently than usual because of the presence of the scientific staff, the rough treatment of the sharks suggested otherwise. A total of 902 blue sharks from 29 fishing sets made during 5 trips were individually examined after being brought aboard the vessel. Additional sharks, most of them large, were caught but not brought aboard. Each shark was categorized as healthy (lively shark hooked in mouth with no obvious trauma), injured (obvious trauma or hook swallowed) or dead. The position of the hook in the shark (mouth, gut or gills) was recorded, as was its sex, fork length and maturity.

To assess post-release mortality of commercially caught blue sharks, a random sample of 40 sharks (both injured and healthy) from the scientifically observed sets were tagged with Wildlife Computers popup archival transmission tags (PATs) just prior to release. Tagged sharks were on deck an average of about $3 \mathrm{~min}$ for tagging and measurement, and showed no obvious stress above and beyond that of capture. A single shark which was dead on retrieval from the fishing gear was also tagged and returned to the water, in order to confirm the tag characteristics of a shark that died after release. Model 4 PATs were deployed in 2004 to 2005, while Mk-10 PATs were deployed in 2006 to 2007. PATs were attached to blue sharks by darting a nylon umbrella tip about $8 \mathrm{~cm}$ into the dorsal musculature of the shark just lateral to the posterior end of the first dorsal fin. The angle of dart insertion was such that the tip engaged the pterygiophores immediately underneath the dorsal fin, thus reducing the possibility of premature release. The umbrella tip was attached to the PAT with a monofilament leader of 400-pound test sheathed to reduce trauma to the shark near the point of insertion. Each PAT was also fitted with an emergency cutoff device which physically released the tag if it went below $1800 \mathrm{~m}$ (which is the maximum nominal safe depth for tag operation).

PATs were programmed to record depth $( \pm 0.5 \mathrm{~m})$, temperature $\left( \pm 0.1^{\circ} \mathrm{C}\right)$ and light intensity at 1 min intervals (model 4 PATs) and $10 \mathrm{sec}$ intervals (Mk-10 PATs) for a period of 2 to 6 mo after release. The length of the recording period was assumed to be long enough to include any mortality due to capture and handling trauma, as well as more extended mortality due to factors such as internal damage or cessation of feeding associated with swallowed hooks. The tag data were internally binned at $6 \mathrm{~h}$ intervals and the summarized data transmitted to an Argos satellite after release of the PAT from the shark. All inferences about shark mortality during the PAT recording period were based on analysis of the satellite-transmitted data. More than $92 \%$ of the tags transmitted successfully after release from the shark. Non-transmitting tags were excluded from subsequent analysis and it was not assumed the shark had died. All PATs were programmed to release from the shark if a constant depth was maintained for a period of $4 \mathrm{~d}$, since a constant depth equal to that of the water depth at that location would be indicative of death in an actively-swimming pelagic shark such as a blue shark.

Overall, blue shark mortality rate due to capture and discard mortality was calculated as the sum of postrelease mortality rates for injured and healthy blue sharks, weighted by the relative frequency of these 2 injury status categories among the 902 scientifically observed sharks, plus the observed frequency of dead sharks among the 902 observations. The 95\% confidence interval around this proportion was calculated based on Monte Carlo draws from the binomial distributions corresponding to both the observed injury status categories and the observed PAT-derived mortalities within each category, as in: $\left(N_{\mathrm{d}}+N_{\mathrm{i}} M_{\mathrm{i}}+N_{\mathrm{h}} M_{\mathrm{h}}\right) \times \mathrm{n}^{-1}$, where the number of sharks $N_{\mathrm{i}}$ is drawn randomly from a binomial distribution with an observed injury status $\left(\mathrm{d}=\operatorname{dead}_{\text {; }} \mathrm{i}=\right.$ injured; $\mathrm{h}=$ healthy), proportion and sample size $\mathrm{n}=902$, and mortality rate $M_{\mathrm{i}}$ is drawn randomly from a binomial distribution with an observed PAT-derived mortality rate and a sample size equal to the number of tags applied to that injury status category.

The probability of survival after discarding was modelled using survival analysis. Analysis was restricted to the 35 sharks where the post-release data were sufficiently complete, including 8 'healthy' sharks and 27 
'injured' sharks. The 2 sharks tagged in 2008 were tagged with short-duration PATs and not included in the survival analysis, although they were included in the overall survival calculations. All survival times were encoded as decimalised days since the day of deployment (e.g. a value of 0.25 indicates a shark which died during the first $6 \mathrm{~h}$ PAT sampling period following deployment).

Techniques of survival analysis following Therneau \& Grambsch (2000) were employed to estimate survivor curves from the filtered dataset. The 'survfit' and 'survreg' functions in version 2.34 of the survival package for version 2.6.2 of the $\mathrm{R}$ statistical programming language (R Development Core Team 2008) were used to implement the analysis. The function 'survfit' was first used to fit the Kaplan-Meier estimate of the rightcensored discrete survival function. The function 'survreg' was then used to fit different parametric models of the survival function assuming no explanatory covariates. Exponential, Weibull, and lognormal survival functions were fitted separately to the data. Relative goodness of fit was evaluated by comparing the corresponding Akaike Information Criterion (AIC) model comparison statistics (Akaike 1973). The bestfitting parametric model was then refit with the following explanatory variables: shark fork length, sex, injury status, hook location, and the interaction between injury status and hook location. The R function 'stepAIC' was used to search stepwise through the offered explanatory variables for a parsimonious saturated model. A stopping rule of a $1 \%$ decrease in model AIC was used to determine whether a candidate variable was accepted during each iteration of the stepwise selection algorithm. Since the analytical stan-

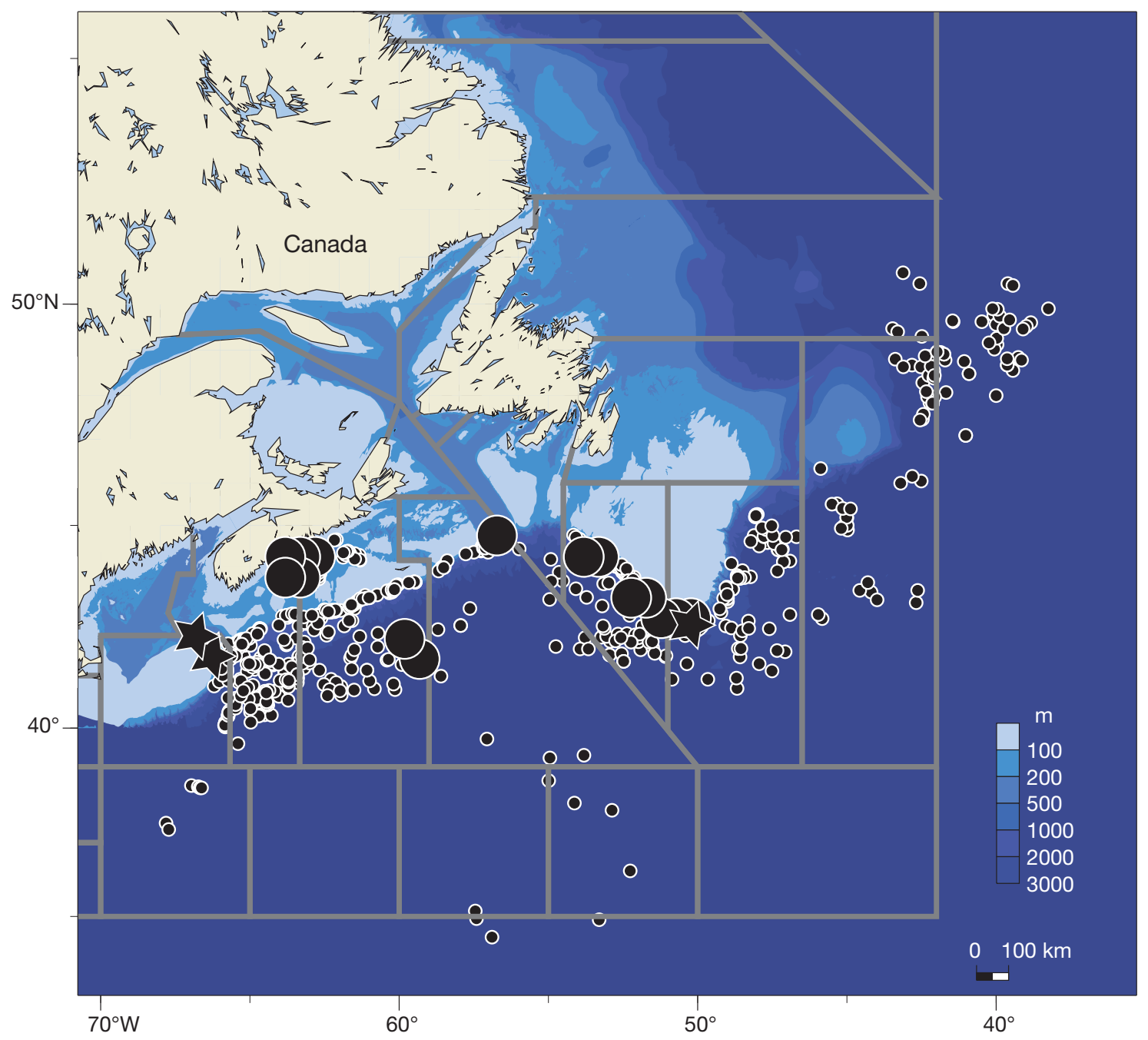

Fig 1. Map showing locations of observed commercial fishing sets (small circles) used in the GLM model, as well as those occupied by scientific staff for injury categorization (stars) and a combination of injury categorization and shark PAT tagging (large circles) 
dard errors were poorly estimated in the lognormal survival model fit (because of the absence of observed mortalities within the 'healthy' shark group), a simple stratified bootstrap algorithm was used to produce appropriate standard error estimates, where the observed data within each injury class were sampled with replacement 9999 times to produce a bootstrap distribution of each model parameter 10000 samples in length.

Estimates of total blue shark catch in the North Atlantic were based on the mean blue shark catch per unit effort (CPUE) of 18.4 sharks 1000 hooks $^{-1}$ (reported by Campana et al. 2006) multiplied by the total North Atlantic longline effort values reported by all countries to ICCAT (ICCAT 2008). Conversion from sharks hook ${ }^{-1}$ to $\mathrm{kg}$ sharks hook ${ }^{-1}$ was based on a mean blue shark fork length of $156.5 \mathrm{~cm}(\mathrm{n}=865)$ recorded by scientific observers in the northwest Atlantic, and corresponding to a live weight of $23.4 \mathrm{~kg}$ using the length-weight conversion factor documented by Campana et al. (2004). Total discards were

Table 1. Analysis of deviance table of the binomial response (alive or dead) generalized linear model examining the survival status of blue sharks at the time of retrieval of the pelagic longline fishing gear. Mortality data represent 12404 observations by international observers on 513 independent fishing sets. Hookid:Hooksize = interaction between hook type and hook size; ResidDf = residual degrees of freedom; ResidDev $=$ residual deviance $; \mathrm{Pr}=$ probability of significance by chi-square test. Terms added sequentially (first to last)

\begin{tabular}{|c|c|c|c|c|c|}
\hline & Df & Deviance & ResidDf & ResidDev & $\mathrm{V} \quad \mathrm{Pr}$ \\
\hline Null & & & 12403 & 8756 & \\
\hline Hook type & 3 & 9.3 & 12400 & 8747 & 0.0257 \\
\hline Surface temp. & 1 & 0.3 & 12399 & 8747 & 0.5760 \\
\hline Soak time & 1 & 47.2 & 12398 & 8700 & $<0.001$ \\
\hline Hook size & 4 & 46.5 & 12394 & 8653 & $<0.001$ \\
\hline Vessel identity & 27 & 362.8 & 12367 & 8290 & $<0.001$ \\
\hline Fork length & 1 & 172.2 & 12366 & 8118 & $<0.001$ \\
\hline Hookid:Hooksize & 1 & 0.6 & 12365 & 8117 & 0.4409 \\
\hline
\end{tabular}

calculated as total catch minus nominal landings, with the latter being those reported to ICCAT (2008). Dead discards were then apportioned based on the mortality rate estimates provided in this study.

\section{RESULTS}

Fishing sets $(n=513)$ in the northwest Atlantic observed by SFOP most often occurred off the Canadian continental shelf in the waters bordering the Gulf Stream (Fig. 1). Of the 71 trips, 55\% used circle hooks, with the remainder using $\mathrm{J}$ or modified $\mathrm{J}$ hooks. The mean soak time of the gear was $19 \mathrm{~h}$, and surface water temperature ranged between 11 and $25^{\circ} \mathrm{C}$, with a mean of $17.1^{\circ} \mathrm{C}$. The mean blue shark catch rate was 98 sharks per set, with a range of 1 to 410 sharks per set.

The proportion of observed blue sharks which were dead upon retrieval of the fishing gear varied between 0 and $100 \%$ in individual sets, with an overall mean of $11.9 \%$. The status of an additional $1.4 \%$ of the sharks (which were unmoving) was unknown, but could mean that the capture mortality rate was closer to $13.3 \%$. Injury rates were inconsistently reported by observers, with $31 \%$ of trips reporting no injured sharks. The proportion of injured sharks reported in the remaining trips was $31.9 \%$.

A GLM of the capture mortality rate in the observed fishing sets indicated that hook type, hook size, soak time, fishing vessel, and shark length were all significant factors in the model, while surface water temperature and the hook type $\times$ hook size interaction were not (Table 1). Fishing vessel explained most of the deviance in the model, suggesting that fishing practices associated with a particular vessel or crew contributed the most to the survival or mortality of a blue shark while on a hook. Shark length was the next most influential variable in the model, with small sharks being more likely to be retrieved dead from the hook. Capture mortality increased with soaktime, and was significantly higher with the $\mathrm{J}$ hook and its variations than with the circle hook $(\mathrm{p}<0.01)$. However, mortality did not change consistently with an increase in hook size.

A more accurate characterization of blue shark capture mortality in relation to injury type and hooking location was available from the scientifically observed fishing sets (Fig. 1). A total of 902 blue sharks from 29 fishing sets and 5 trips were closely examined after being brought aboard the vessel for examination (Table 2). When averaged across years with each year being weighted equally, hooking mortality was assessed at $20 \%$, with $44 \%$ injured and $36 \%$ classed as healthy. Most of the sharks ( $80 \%$ ) were hooked in the mouth or jaw, while $20 \%$ had swallowed the hook. There was a clear association between hooking location and the severity of the injury, with $96 \%$ of the sharks that had swallowed the hook being injured or dead, and $41 \%$ of all dead having swallowed the hook. In contrast, $97 \%$ of the sharks classified as being healthy had been hooked in the mouth or jaw. Logistic regression indicated that there was no significant relationship between mortality rate and shark length $(\mathrm{p}>$ 0.5), in contrast to the results of our GLM model.

A subsample $(\mathrm{n}=40)$ of the scientifically observed blue sharks were tagged with PATs and released to 
Table 2. Prionace glauca. Injury status of blue sharks caught on commercial fishing vessels, as observed by scientific staff. $\mathrm{C}=$ circle hook

\begin{tabular}{|c|c|c|c|c|c|c|c|c|c|c|c|c|c|}
\hline Date & Fishery & $\begin{array}{l}\text { Hook } \\
\text { type }\end{array}$ & $\begin{array}{c}\text { Water } \\
\text { temp } \\
\left({ }^{\circ} \mathrm{C}\right)\end{array}$ & $\begin{array}{c}\text { No. } \\
\text { blue } \\
\text { sharks }\end{array}$ & $\overline{\text { Fins }}$ & $\begin{array}{l}\text { Hoo } \\
\text { Gills }\end{array}$ & $\begin{array}{l}\text { king } \\
\text { s Gut }\end{array}$ & $\begin{array}{l}\text { location } \\
\text { Mouth/ } \\
\text { jaw }\end{array}$ & $\begin{array}{l}(\%)- \\
\text { Unknown }\end{array}$ & $\begin{array}{c}\text { Mean } \\
\text { range fork } \\
\text { length }(\mathrm{cm})\end{array}$ & $\begin{array}{r}\text { Inju } \\
\text { Healthy }\end{array}$ & $\begin{array}{l}\text { ry status } \\
\text { Injured }\end{array}$ & $\begin{array}{l}(\%) \\
\text { Dead }\end{array}$ \\
\hline Sep 2003 & Blue shark & \#16 C & 18 & 106 & 0 & 0 & 0 & 0 & 100 & $208(113-293)$ & 38 & 45 & 17 \\
\hline Sep 2005 & Swordfish & $50 \%$ \# $\mathrm{J}$ and $50 \%$ \#16 C & 222 & 68 & 0 & 3 & 32 & 49 & 16 & 179 (101-272) & 46 & 44 & 10 \\
\hline Oct 2006 & Swordfish & $33 \%$ \#9 J and $66 \%$ \#16 C & 16 & 61 & 0 & 0 & 38 & 54 & 8 & $147(113-209)$ & ) 20 & 60 & 20 \\
\hline Sep 2007 & Swordfish & $33 \%$ \#9 J and $66 \%$ \#16 C & 17 & 93 & 1 & 0 & 6 & 69 & 24 & $138(79-215)$ & 30 & 44 & 26 \\
\hline Sep 2008 & Swordfish & \#16 C & $16-21$ & 574 & 1 & 0 & 14 & 76 & 9 & $148(71-251)$ & 45 & 28 & 27 \\
\hline
\end{tabular}

Table 3. Prionace glauca. Summary of blue sharks tagged with pop-up archival tags

\begin{tabular}{|lrrrr|}
\hline $\begin{array}{l}\text { Tagging } \\
\text { date }\end{array}$ & $\begin{array}{r}\text { No. ind. } \\
\text { tagged }\end{array}$ & $\begin{array}{c}\text { Trans- } \\
\text { mitted }\end{array}$ & Fork length (cm) & No. ind. \\
mean (range) & died \\
\hline Aug-Sep 2005 & 10 & 8 & $185(151-251)$ & 1 \\
Sep-Oct 2006 & 15 & 15 & $150(125-177)$ & 4 \\
Sep 2007 & 13 & 12 & $154(124-190)$ & 3 \\
Sep 2008 & 2 & 2 & $165(139-190)$ & 1 \\
\hline
\end{tabular}

document post-release mortality (Table 3). The sharks that were tagged were almost all less than $200 \mathrm{~cm}$ in fork length and sexually immature. Both healthy and injured sharks were tagged and released. All but 3 of the tags transmitted successfully. The recording time of the PATs ranged between 5 and $210 \mathrm{~d}$, with a mean time of $61 \mathrm{~d}$, although one-third of the tags from surviving sharks reported prematurely by an average of $16 \mathrm{~d}$.

Although the PATs do not explicitly transmit mortality data, the depth-temperature data provided a strong inference about the mortality status of the shark. To validate this inference, a blue shark which had died on the hook was tagged and released as soon as it was brought on board. The data subsequently transmitted by this tag indicated that the dead shark immediately sank to the bottom of the ocean and remained there for $5 \mathrm{~d}$, as indicated by a constant depth equal to the water depth at that location and a nearly constant temperature (Fig. 2A). After $5 \mathrm{~d}$, the constant-depth warning function of the PAT released the tag and allowed it to float to the surface and transmit, as indicated by the ascending depth record on the final day. In contrast, tags on surviving blue sharks, whether injured or not, indicated that the living sharks remained in the water column, well up from the bottom, and engaged in regular or irregular dives to various depths (Fig. 3). Tags where the dart head had prematurely fallen out of the shark were clearly identifiable as such, since the unattached tags did not sink, but floated to the surface. Therefore, the depth records of dead and live sharks clearly differentiated them from each other, as well as from non-functioning tags.

Visual interpretation of the depth-temperaturetime plots of surviving sharks suggested the presence of a recovery period from the stress of capture immediately after return to the water (Fig. 3). This presumed recovery period was apparent as a period of depthholding behaviour (little or no movement to other depths) in relatively shallow water for periods of 1 to $27 \mathrm{~d}$. Post-release residency at a constant depth $( \pm 10 \mathrm{~m})$ during the recovery period averaged $4.0 \mathrm{~d}$ (SE $=0.7)$, while that at a slightly broader constant depth $( \pm 15 \mathrm{~m})$ averaged $8.3 \mathrm{~d}(\mathrm{SE}=1.3)$. The mean depths occupied during and after this recovery period were $30 \mathrm{~m}(\mathrm{SD}=41)$ and $131 \mathrm{~m}(\mathrm{SD}=190)$, respectively. Some sharks initiated deep-diving behaviour after encountering a warm water mass, whose temperature exceeded that of the initial water mass by more than $5^{\circ} \mathrm{C}$ (e.g. Fig. 3C). In such cases, it is quite likely that the abrupt change in shark depth was due to the entrance into a different water mass rather than the end of a recovery period.

If the depth-holding behaviour immediately after release was indeed a recovery period, it would be expected to differ between injured and healthy sharks. Sharks classified as healthy at the time of release spent fewer days (mean of $2.4 \mathrm{~d}$ ) post-release at a constant depth (defined as $\pm 10 \mathrm{~m}$ from the first day's timeweighted depth) compared to injured sharks (4.7 d), but the difference was not statistically significant $(p>0.1)$. However, the initial time-weighted depth $(<1$ d after release) was significantly deeper $(p<0.05)$ for seriously injured sharks (109 m, SE = 14) compared to injured (49 m, SE = 9) and healthy sharks (36 m, SE = 9), and for sharks that had swallowed the hook (146 m, SE = 19) compared to mouth-hooked sharks (56 m, SE = 7). Similarly, defining the recovery period as the number of days during which the standard deviation of daily timeweighted depth remained less than 20, healthy sharks had shorter recovery periods $\left(6.9 \mathrm{~d}_{i} \mathrm{SE}=2.4\right)$ than injured sharks, which all exceeded $20 \mathrm{~d}(\mathrm{SE}=8)$. However the difference was again not significant $(p=0.12)$. 


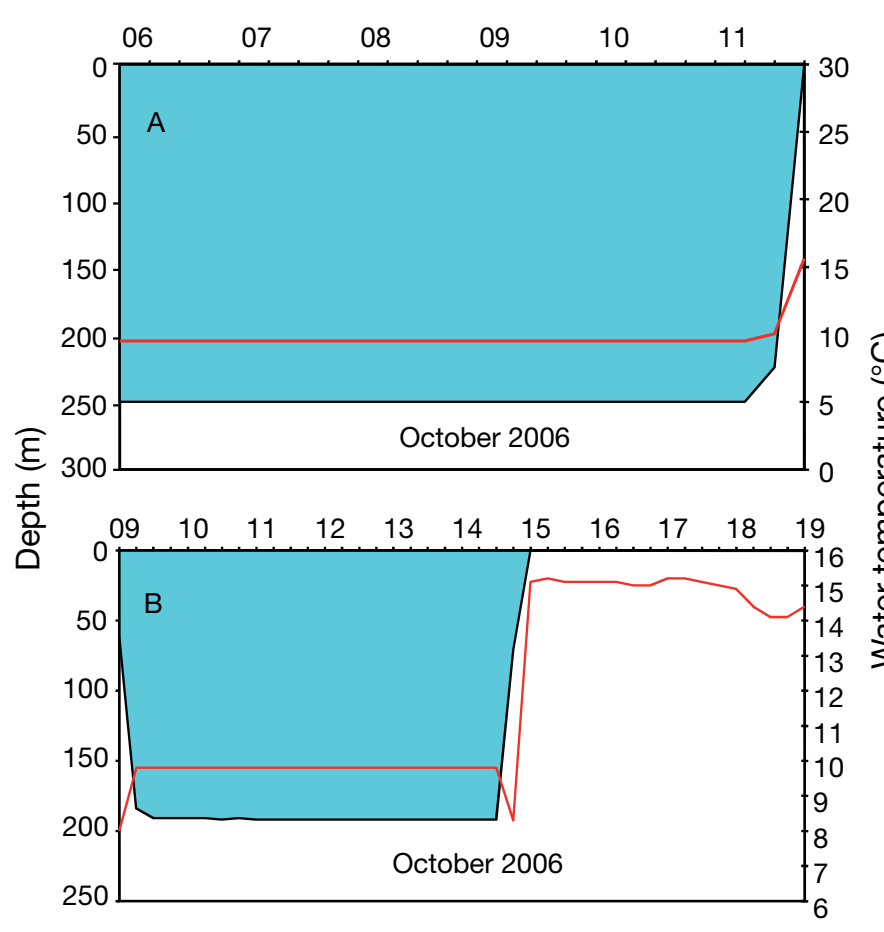

Fig. 2. Prionace glauca. Time vs. depth-temperature plots for blue sharks discarded at sea. Mean depth weighted by timeat-depth is shown in blue; time-weighted temperature indicated by red line. (A) Shark known to be dead at time of discarding. (B) Shark which appeared to have died shortly after discarding

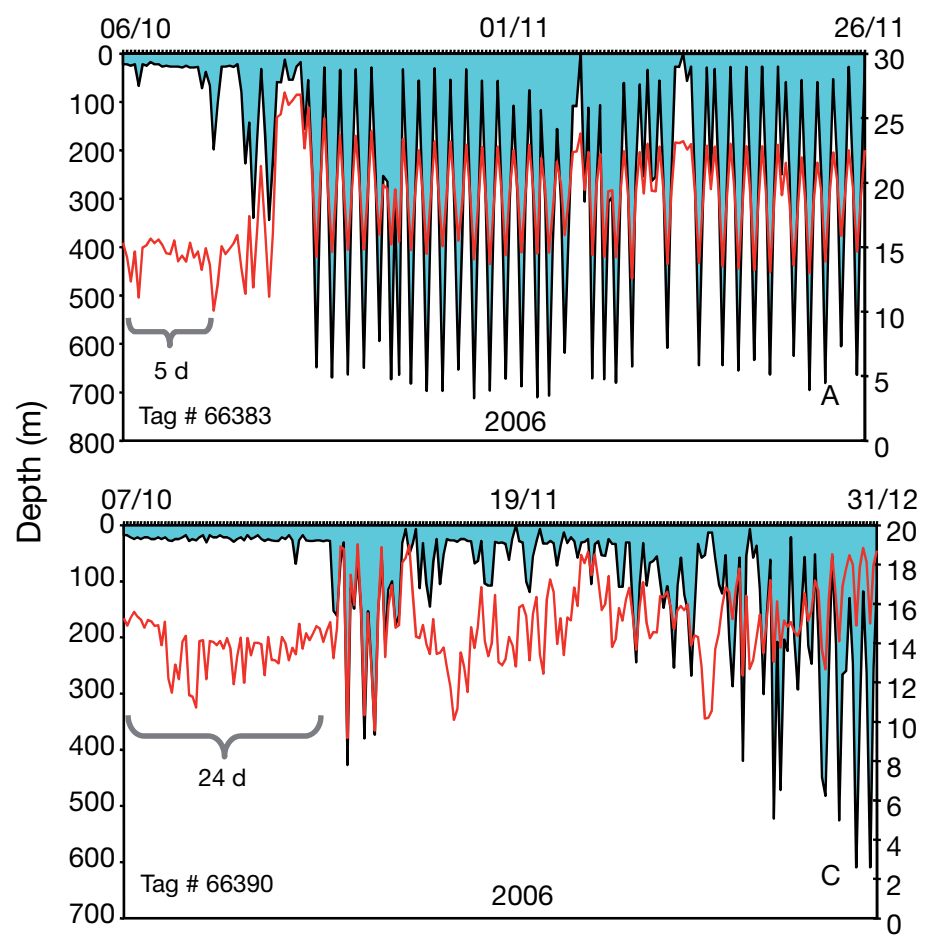

The time-depth pattern consistent with mortality was observed in 9 sharks, all of which were injured on release. Eight of these sharks sank to, and remained on, the bottom until the tag released (Fig. 2B). The final shark apparently died near the surface where the ocean bottom was $>1800 \mathrm{~m}$, which caused the emergency cutoff switch to release the PAT prematurely when the shark sank. Death was inferred by the fact that the shark had spent the previous $9 \mathrm{~d}$ at depths of $<50 \mathrm{~m}$, then abruptly descended to $1880 \mathrm{~m}$ in less than $12 \mathrm{~h}$.

Post-release mortality did not occur randomly across injury types or hook locations. Based on the PAT data, none of the $10(0 \%)$ healthy blue sharks (all of which were hooked in the mouth or jaw) died after release. In contrast, 3 of $8(38 \%)$ of the injured sharks which had swallowed the hook died, as did 6 of 19 (32\%) of the injured sharks hooked in the mouth. Overall, 33\% of the injured sharks died post-release.

Survival models which accounted for injury provided a markedly better fit to the data than did simpler models. Among the simple models, the AIC statistics indicated that the lognormal model provided the best fit to the data (Tables $4 \& 5$ ), although the survivor curves from the Weibull and lognormal models were difficult to distinguish by eye (Fig. 4). The fit to the discrete Kaplan-Meier model was comparable (Fig. 4). Of the predictor terms offered to the

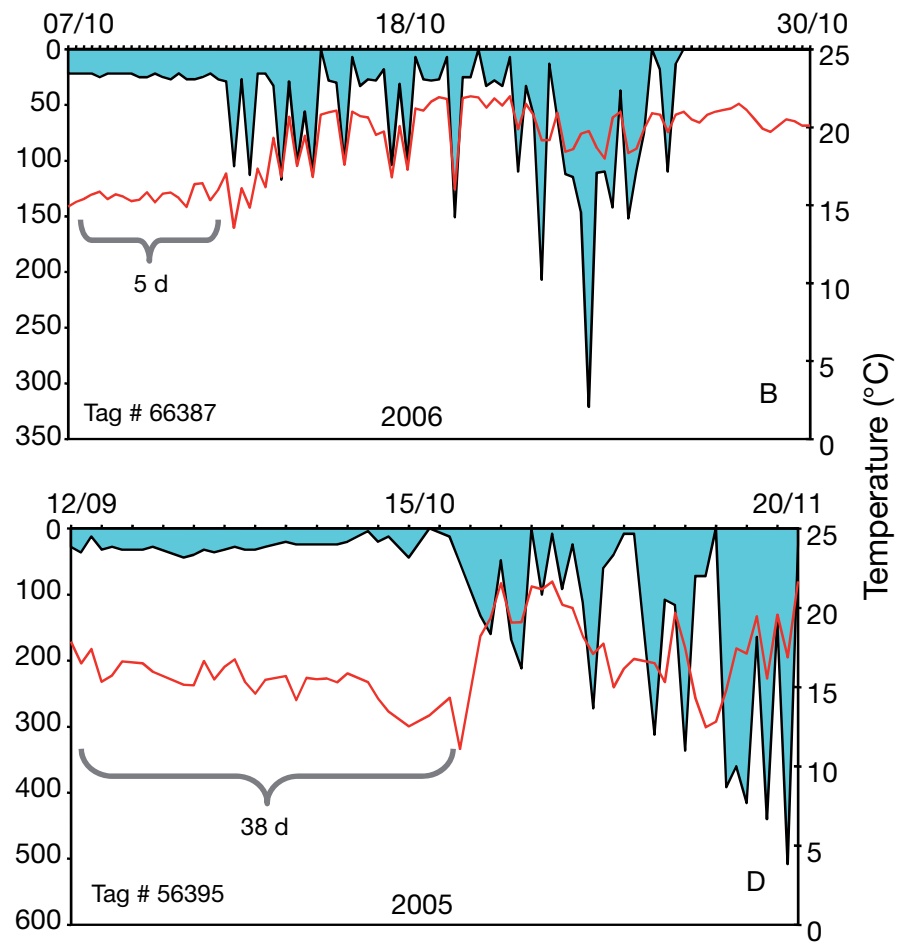

Fig. 3. Prionace glauca. Time-depth-temperature plots for healthy $(\mathrm{A}, \mathrm{B})$ and injured $(\mathrm{C}, \mathrm{D})$ blue sharks discarded at sea. Mean depth weighted by time-at-depth is shown in blue; time-weighted temperature indicated by red line. Horizontal bracket indicates presumed recovery period after discarding, based on stability in depth occupied 
Table 4. Numerical output from the simple and saturated Kaplan-Meier blue shark survivor model fits

\begin{tabular}{|c|c|c|c|c|c|c|c|c|}
\hline \multirow[t]{2}{*}{ Model } & \multirow{2}{*}{$\begin{array}{l}\text { Data } \\
\text { subgroup }\end{array}$} & \multirow{2}{*}{$\begin{array}{l}\text { Time of } \\
\text { death (d) }\end{array}$} & \multirow{2}{*}{$\underset{\text { risk }}{\text { Number at }}$} & \multirow{2}{*}{$\begin{array}{c}\text { Number of } \\
\text { deaths }\end{array}$} & \multirow[t]{2}{*}{ Survival } & \multirow[t]{2}{*}{$\mathrm{SE}$} & \multicolumn{2}{|c|}{$95 \%$ CI bounds } \\
\hline & & & & & & & Lower & Upper \\
\hline \multirow[t]{4}{*}{ Simple } & All & 0.25 & 35 & 6 & 0.829 & 0.064 & 0.658 & 0.919 \\
\hline & & 6.29 & 29 & 1 & 0.800 & 0.068 & 0.626 & 0.899 \\
\hline & & 7.00 & 28 & 1 & 0.771 & 0.071 & 0.595 & 0.879 \\
\hline & & 12.00 & 27 & 1 & 0.743 & 0.074 & 0.564 & 0.857 \\
\hline \multirow[t]{5}{*}{ Saturated } & Healthy & - & 8 & 0 & 1.000 & - & - & - \\
\hline & Injured & 0.25 & 27 & 6 & 0.778 & 0.080 & 0.571 & 0.893 \\
\hline & & 6.29 & 21 & 1 & 0.741 & 0.084 & 0.532 & 0.867 \\
\hline & & 7.00 & 20 & 1 & 0.704 & 0.088 & 0.494 & 0.839 \\
\hline & & 12.00 & 19 & 1 & 0.667 & 0.091 & 0.457 & 0.811 \\
\hline
\end{tabular}

Table 5. Numerical output from the simple and saturated parametric blue shark survivor model fits. Model output is shown in terms of the Akaike Information Criterion (AIC), $Z$ statistic $(Z)$ and probability value $(\mathrm{p}) ; \mathrm{n}$ is the number of free parameters in the fitted model

\begin{tabular}{|c|c|c|c|c|c|c|c|c|}
\hline Model & Distribution & AIC & $n$ & Parameter & Estimate & SE & $Z$ & $\mathrm{p}$ \\
\hline Simple & Exponential & 118.2528 & 1 & $\begin{array}{l}\beta_{\text {All }} \\
\ln \sigma\end{array}$ & $\begin{array}{l}5.47 \\
1^{\mathrm{a}}\end{array}$ & $\begin{array}{c}0.333 \\
-\end{array}$ & $\begin{array}{c}16.4 \\
-\end{array}$ & $\begin{array}{c}<0.0001 \\
-\end{array}$ \\
\hline Simple & Weibull & 96.8206 & 2 & $\begin{array}{l}\beta_{\text {All }} \\
\ln \sigma\end{array}$ & $\begin{array}{l}8.16 \\
1.19\end{array}$ & $\begin{array}{l}1.705 \\
0.312\end{array}$ & $\begin{array}{l}4.78 \\
3.80\end{array}$ & $\begin{array}{l}<0.0001 \\
<0.0001\end{array}$ \\
\hline Simple & Lognormal & 94.6782 & 2 & $\begin{array}{l}\beta_{\text {All }} \\
\ln \sigma\end{array}$ & $\begin{array}{l}7.27 \\
1.61\end{array}$ & $\begin{array}{l}1.670 \\
0.286\end{array}$ & $\begin{array}{l}4.35 \\
5.62\end{array}$ & $\begin{array}{l}<0.0001 \\
<0.0001\end{array}$ \\
\hline Saturated & Lognormal & 80.4089 & 3 & $\begin{array}{c}\beta_{\text {Healthy }} \\
\beta_{\text {Injured }} \\
\ln \sigma\end{array}$ & $\begin{array}{r}38.49 \\
6.38 \\
1.74\end{array}$ & $\begin{array}{l}6.089 \\
2.119 \\
0.169\end{array}$ & $\begin{array}{r}0.0040 \\
-0.0034 \\
6.228\end{array}$ & $\begin{array}{l}<0.0001 \\
<0.0001 \\
<0.0001\end{array}$ \\
\hline
\end{tabular}

saturated lognormal model, only injury status was accepted by the stepwise fitting algorithm (Table 5). The Kaplan-Meier model was then refit assuming the

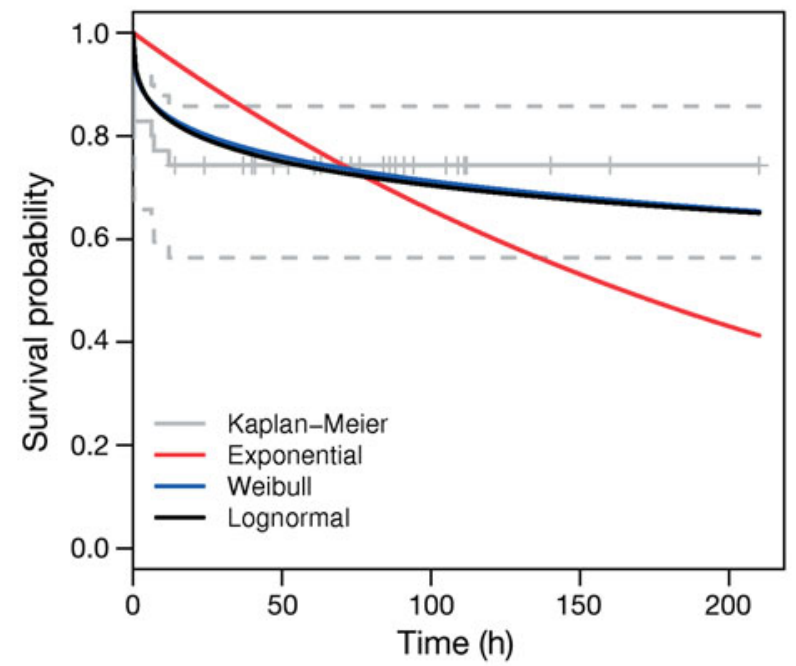

Fig. 4. Prionace glauca. Survival probability as a function of time (h) post-release under 4 candidate survival models. The grey dashed line indicates the $95 \%$ confidence interval around the discrete Kaplan-Meier model; crosses represent censored observations same structure (i.e. different survivor curves for injured and healthy sharks; Table 4). As none of the healthy sharks died, the survivor curves for the healthy sharks from both the saturated Kaplan-Meier and saturated lognormal model fits were flat (Fig. 5). The survivor curve for the injured sharks was very similar for both the saturated Kaplan-Meier and saturated lognormal model fits (Fig. 5), and indicated that $50 \%$ of the non-surviving sharks would be expected to die within $0.9 \mathrm{~d}$ of release, and $95 \%$ within $11.3 \mathrm{~d}$ of release.

Total bycatch mortality rate can be calculated by weighting the injury-specific mortality rates $0 \%$ for healthy; $33 \%$ for injured; $100 \%$ for dead on hook) by the relative frequency of scientifically observed injury categories (36\% healthy; $44 \%$ injured; $20 \%$ dead on hook). Since there was no appreciable difference in mortality rate due to hook location within the injured category, hook location was not used as a weighting factor. Overall bycatch mortality was thus calculated as $35 \%$. The $95 \%$ confidence interval around this estimate based on Monte Carlo simulation was 28 to $44 \%$. The estimated discard mortality for sharks that were released alive (excluding those which died on the hook) was $19 \%$, with a $95 \%$ confidence interval of 10 to $29 \%$. 


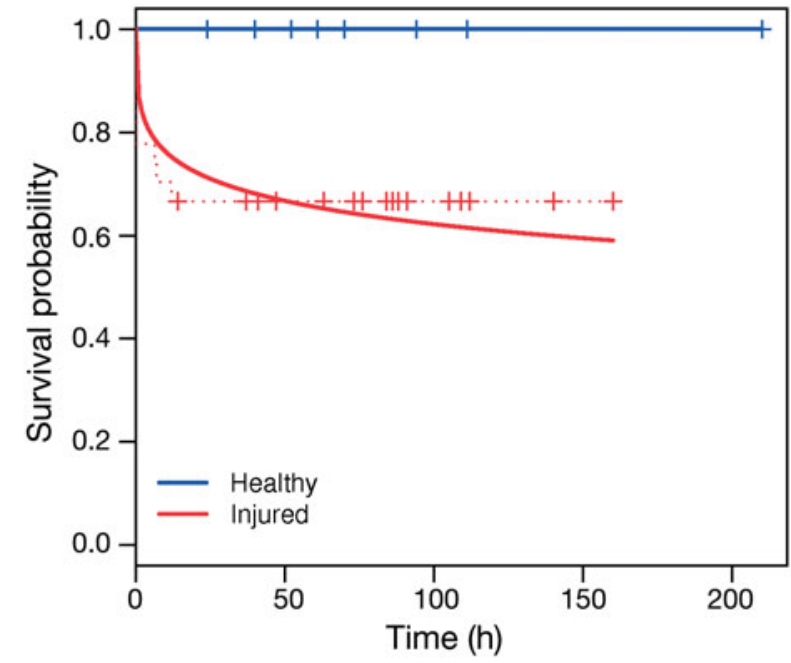

Fig. 5. Prionace glauca. Survival probability as a function of time (h) post-release for injured and healthy sharks under the revised Kaplan-Meier (dotted line) and the saturated lognormal (solid line) model. Crosses represent censored observations

Nominal catch of blue shark in the North Atlantic averaged about $24000 \mathrm{t}$ annually between the years 2000 to 2006 (Table 6). These catch statistics seldom include discards, whether alive or dead, and are believed to grossly underestimate actual catch (ICCAT 2008). Analysis of observed trips by Canadian pelagic longliners targeting tuna and swordfish in international waters of the northwest Atlantic indicated a mean blue shark catch rate of $790 \mathrm{~kg} 1000$ hooks $^{-1}$ $(\mathrm{SE}=50 ; \mathrm{n}=505$ sets $)$, corresponding to 33.7 sharks 1000 hooks $^{-1}$ based on a mean individual shark weight of $23.4 \mathrm{~kg}$. Taking into account a range of published CPUE values from several countries fishing for sharks in the North Atlantic, Campana et al. (2006) reported a mean recent blue shark CPUE of 18.4 sharks 1000 hooks $^{-1}$, corresponding to $430 \mathrm{~kg} 1000$ hooks $^{-1}$. This latter, more conservative catch rate estimate was multiplied by estimates of total pelagic longline effort in

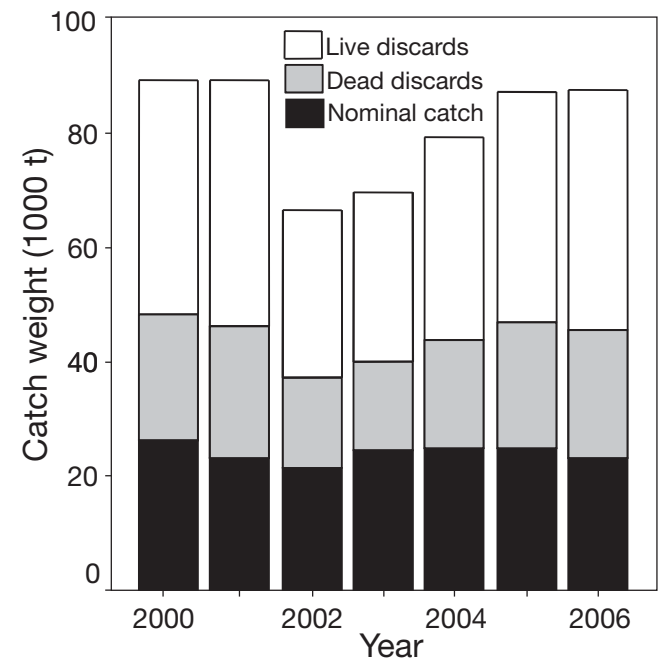

Fig. 6. Prionace glauca. Nominal landings and calculated live and dead discards of blue sharks in the North Atlantic

the North Atlantic to calculate a total estimated annual blue shark catch of about $84000 \mathrm{t}$ (Table 6). Calculated discards were therefore about $57000 \mathrm{t}$ annually, which is more than twice as much as the nominal catch (Fig. 6). If the overall bycatch mortality rate of $35 \%$ calculated in this study is assumed to apply to the nonCanadian components of the North Atlantic swordfish fishery (an assumption which is tenuous at best), a recent annual average of over $20000 \mathrm{t}$ of dead discards of blue sharks in the North Atlantic would result (Table 6). Dead discards would therefore account for about $24 \%$ of the total estimated annual catch, and would be almost equal in magnitude to the nominal catch (Table 6, Fig. 6).

\section{DISCUSSION}

Our results indicated that the overall mortality rate of blue sharks caught as part of Canadian commercial

Table 6. Prionace glauca. Reported and estimated total catch plus discards of blue sharks in the North Atlantic

\begin{tabular}{|c|c|c|c|c|c|c|c|}
\hline Year & $\begin{array}{l}\text { Nominal } \\
\text { catch }(\mathrm{t})\end{array}$ & $\begin{array}{l}\operatorname{ICCAT}^{\mathrm{a}} \\
\text { catch }(\mathrm{t})\end{array}$ & $\begin{array}{c}\text { Effort } \\
\left(1000 \text { hooks }^{-1}\right)\end{array}$ & $\begin{array}{c}\text { CPUE } \\
\left.\text { (t 1000 hooks }{ }^{-1}\right)\end{array}$ & $\begin{array}{c}\text { Total estimated } \\
\text { catch }(\mathrm{t})\end{array}$ & $\begin{array}{l}\text { Calculated } \\
\text { discards (t) }\end{array}$ & $\begin{array}{c}\text { Calculated discard } \\
\text { mortality }(\mathrm{t})\end{array}$ \\
\hline 2000 & 25958 & 31021 & 218542 & 0.43 & 93973 & 62952 & 22033 \\
\hline 2001 & 22670 & 27713 & 218470 & 0.43 & 93942 & 66229 & 23180 \\
\hline 2002 & 20917 & 25983 & 165841 & 0.43 & 71312 & 45329 & 15865 \\
\hline 2003 & 24021 & 26493 & 166565 & 0.43 & 71623 & 45130 & 15795 \\
\hline 2004 & 24367 & 25510 & 186693 & 0.43 & 80278 & 54768 & 19169 \\
\hline 2005 & 24608 & 25707 & 204497 & 0.43 & 87934 & 62227 & 21779 \\
\hline 2006 & 22731 & 26795 & 212449 & 0.43 & 91353 & 64558 & 22595 \\
\hline
\end{tabular}


pelagic longliner swordfishing operations in the northwest Atlantic is about $35 \%$, and that the post-release mortality by itself is about $19 \%$. Although it is widely assumed that post-release mortality can be a major source of unquantified fishing mortality (Davis 2002, Pollock \& Pine 2007), few have speculated about the mortality rate in blue sharks. Recent studies which applied PATs to marlin have demonstrated that even fish which were handled carefully as part of a recreational hook and line fishery could sustain substantial postrelease mortality rates. For example, the mortality rate of striped marlin Tetrapturus audax and white marlin Tetrapturus albidus after release was $26 \%$ and $17 \%$, respectively (Domeier et al. 2003, Horodysky \& Graves 2005). However, it is possible that marlin are more fragile than some shark species. A physiological study on sharks suggested that oxygen delivery was not necessarily compromised following exhaustive exercise, and that hook and line capture and subsequent release did not increase mortality, at least in juvenile sandbar sharks Carcharhinus plumbeus (Brill et al. 2008). Even by shark standards, the blue shark is known to be a hardy shark species, and individuals are often recovered with one or more hooks in their bodies from previous captures (Borucinska et al. 2002, S. E. Campana pers. obs.). Consistent with this expectation was a reported blue shark post-release mortality rate of only 5 to $10 \%$ in the Pacific Ocean (Moyes et al. 2006). This post-release mortality rate is much lower than the $19 \%$ observed in this study. However, there are 2 critical differences between this study and that of Moyes et al. (2006). (1) The Moyes et al. (2006) study PAT-tagged only blue sharks which were considered healthy. Moribund sharks were caught and examined, but not tagged. As a result, their observation of $100 \%$ survival of all PAT-tagged sharks was based only on healthy animals, with the overall $90 \%$ survival estimate based on biochemical indices. Therefore, the $100 \%$ survival rate in healthy blue sharks found by Moyes et al. (2006) is in fact identical to that reported here. (2) This study focused on sharks caught during commercial fishing operations, and which were thus exposed to handling conditions very different to those of the scientific research cruise of Moyes et al. (2006). At a minimum, commercially caught sharks can be expected to have spent longer on the hook, and to be treated considerably less gently than those caught for scientific purposes. Although it is possible that our post-release mortality rates are not representative of other areas and fisheries, there is no reason to think that our mortality rates are biased to the high side; indeed, it is possible that the presence of scientific staff on board the fishing vessels resulted in more gentle handling of the sharks from the fishing crew, and thus better survival, than if the scientific staff had been absent.
There was a very clear linkage between the extent of trauma visible on the shark at the time of release and its subsequent survival probability: all apparently healthy sharks survived, while $33 \%$ of those that were badly injured or gut hooked subsequently died. Parallel results were reported by Domeier et al. (2003), who observed $100 \%$ mortality in striped marlin hooked in the gills and $63 \%$ mortality in those that had swallowed the hook. In contrast, only $9 \%$ of the healthy marlin subsequently died. Similarly, most of the postrelease mortality in white marlin was associated with gut-hooked fish (Horodysky \& Graves 2005). The internal injuries associated with gut-hooking were not evaluated in this study, but must have been more extensive than those reported for white-spotted charr Salvelinus leucomaenis, where gut-hooked fish experienced $>90 \%$ post-release survival (Tsuboi et al. 2006). Nevertheless, it is clear that the blue shark mortality associated with gut-hooking was due to trauma, rather than interference with digestion and subsequent starvation; the survival time models indicated that if sharks were going to die after release, one-half would die in less than $1 \mathrm{~d}$, and that $95 \%$ would die within $11 \mathrm{~d}$. Such a short period of survival is inconsistent with death by starvation, which would presumably take many weeks. Rapid post-release mortality has also been observed in the marlin studies, where most of the mortality occurred within $1.5 \mathrm{~d}$ of release (Domeier et al. 2003, Horodysky \& Graves 2005).

The fact that post-release mortality (19\%) was comparable to hooking mortality ( $20 \%$ by scientific staff; 12 to $13 \%$ by fisheries observers) in our study indicates that observer estimates of blue shark capture mortality are likely to provide a gross underestimate of total mortality due to fishing. The explanation for the lower hooking mortality estimate by fisheries observers could be that the estimates by scientific staff were based on a relatively small number of scientifically observed trips, and thus might not be fully representative of the swordfish fishery. The difference, however, is also explained by the hands-on examination of the sharks by scientific staff, and the fact that it is extremely difficult for any observer to assess shark status when the hook is cut off or removed from the shark at the rail, and the shark immediately discarded. Published estimates of blue shark hooking mortality in other pelagic longline fisheries generally mirror our own, with 7 to $31 \%$ reported for US pelagic longliners in the northwest Atlantic (Diaz \& Serafy 2005, Kerstetter \& Graves 2006, Table 2.4 in ICCAT 2008), and about $14 \%$ in the New Zealand tuna longline fishery (Francis et al. 2001). Our GLM analysis suggested that hook type, hook size, soak time, fishing vessel, and shark length all contributed to hooking mortality, but that the fishing vessel and shark length were the major 
factors. Several other published studies on blue shark hooking mortality have also reported that J hooks produce higher mortality in blue sharks than circle hooks (Kerstetter \& Graves 2006, Kaplan et al. 2007), presumably because circle hooks are more likely to be hooked in the mouth rather than swallowed, and our study supports that conclusion. Other reported factors which apparently increased blue shark hooking mortality were longer soak times, warmer water temperatures and smaller sharks (Francis et al. 2001, Diaz \& Serafy 2005).

The presence of a post-release behavioural recovery period in large pelagic fishes is consistent with the stress of capture. Capture on a longline is likely to be a stressful event, given that it involves up to $12 \mathrm{~h}$ on a hook in a restricted area, with limited water flow over the gills. Biochemical indices of the stress of capture have been characterized in one shark species (Moyes et al. 2006, Skomal 2007, Brill et al. 2008), with biochemical recovery typically taking up to $24 \mathrm{~h}$. This period is somewhat shorter than our observations of healthy blue sharks, where behavioural recovery took 2 to $7 \mathrm{~d}$, depending on the recovery measure used. Recovery was 3 to 10 times longer for injured sharks, presumably due to the requirement for tissue repair. Since biochemical indices of capture stress have not been reported for blue sharks, there is not necessarily a discrepancy between the biochemical and behavioural recovery periods. Presumably however, the depth-holding behaviour of both healthy and injured recovering sharks is associated with a cessation of feeding. Kerstetter et al. (2003) also reported depthholding behaviour of blue marlin Makaira nigricans in surface waters after release, with some tendency to move into cooler waters.

This study was not designed to evaluate measures for reducing capture and post-release mortality of blue sharks. Nevertheless, several principles became clear during the study. Given that both capture and postrelease mortality were elevated if the shark suffered severe trauma, and since the strong vessel effect likely reflects handling practices which can influence the level of injury and trauma, changes in handling practices on the part of the fishing crew could undoubtedly increase survival. Ripping the hook out of the fish (which occasionally removed the jaw) and bodygaffing were 2 practices which often produced severe trauma in the sharks. The replacement of J hooks with circle hooks would be one simple approach to reduce the probability of gut-hooking (Kerstetter \& Graves 2006) and thus increase survival. Some artificial baits reduced the catch of bycatch species relative to the target species in other fisheries (Erickson \& Berkeley 2008). A reduced longline soak time may also reduce the catch rate of sharks (Ward et al. 2004, Erickson \&
Berkeley 2008), although if it also reduced the catch rate of billfish, there may be no net gain. The use of nylon leaders (as opposed to wire leaders) has been reported to reduce shark bycatch mortality (Ward et al. 2008), but only under the assumption that sharks that bite off the hooks subsequently survive. In the case of swallowed hooks, that assumption is questionable. Alternative measures such as the use of rare earth metal and magnetic deterrents and other possible mitigation measures are discussed elsewhere (Mandelman et al. 2008, Stoner \& Kaimmer 2008).

The results of this study demonstrate that PAT tags are extremely well suited for estimating post-release mortality rates in sharks. The interpretation of death from the telemetered PAT data was unambiguous; for an active pelagic shark, there are few alternative explanations for a rapid descent below $1800 \mathrm{~m}$, or to the ocean floor with no subsequent movement. Such behaviour would not necessarily be the case in shark species whose regular diving behaviour sometimes exceed depths of $1800 \mathrm{~m}$, such as porbeagles Lamna nasus (S. E. Campana, unpubl.), unless they happen to be over the continental shelf. The advantages of PAT tags for quantifying post-release mortality rate presumably extend to any teleost fishes with sufficient vertical movement in order to be able to detect mortality or premature release of the tag, and which are large enough to carry the tag, such as has been demonstrated for marlins (Domeier et al. 2003, Horodysky \& Graves 2005). The disadvantage of PAT tag use is largely related to cost $(\sim 3500$ per tag), with the attendant implications for sample size. Although the use of 40 PATs in this study gave estimates of discard mortality accurate to $\pm 10 \%$, sample sizes of more than 100 would be required to reduce this uncertainty to $\pm 5 \%$ (Horodysky \& Graves 2005), which would be quite expensive. Alternative approaches to estimating discard mortality can be less expensive, but at the expense of rigour. Ultrasonic telemetry has been used effectively to estimate discard mortality, but because of the requirement to actively track the tagged fish after release, was suited only for quantifying short-term mortality, on the order of hours or days (Gurshin \& Szedlmayer 2004). Pen- or cage-rearing after capture can also provide useful short-term mortality measures (Neilson et al. 1989, Mandelman \& Farrington 2007), but confounds cage effects with mortality, and ignores mortality from predation or starvation. In the longer term, the use of biochemical indices such as blood stress factors promise to provide indirect measures of the likelihood of post-release mortality. However, it is important to recognize that such measures are only useful if linked directly at some point to actual measurements of discard mortality, such as those provided by PAT tags (Davis 2002, Pollock \& Pine 2007, Skomal 2007). 
There are no precise estimates of the total blue shark catch in the North Atlantic, but ICCAT (2008) estimated the catch weight at about $27000 \mathrm{t}$ annually from 2000 to 2006, based on catch ratios with commercially fished large pelagic species. Although larger than the nominal catch, this estimate may be conservative. Clarke (2008) used analyses of the shark fin trade in Hong Kong to estimate the total Atlantic blue shark catch at about 170000 t, of which about $100000 \mathrm{t}$ would come from the North Atlantic, based on longline effort ratios between north and south (ICCAT 2008). Campana et al. (2006) also estimated the North Atlantic blue shark catch at about 100000 t, based on observer catch ratios between blue sharks and large pelagic target species. The total catch estimate of $84000 \mathrm{t}$ calculated in the current study is slightly lower, suggesting that the associated discard estimate of $57000 \mathrm{t}$ arising from this study may be conservative. Nevertheless, it is clear that blue sharks are a major component of the pelagic longline catch in the North Atlantic, accounting for one-third of the Canadian large pelagic catch (Campana et al. 2006), one-half of the US pelagic longline catch (Mandelman et al. 2008), and more than half of the Spanish pelagic longline fishery for swordfish (Mejuto et al. 2008). Given that the total bycatch mortality rate estimates calculated in this study were based on only a single component of the North Atlantic swordfish fishery, it would be presumptuous to apply these rates to an entire multinational fishery encompassing a range of shark handling practices. As a coarse approximation however, the dead discard estimate of $20000 \mathrm{t}$ reported in this study, corresponding to 860000 blue sharks, is clearly of considerable magnitude, and could play an important role in ICCAT's future attempts to develop a stock assessment for blue sharks in the North Atlantic. Dead discard estimates are not yet incorporated into ICCAT shark assessments, yet they would substantially increase estimates of fishing mortality, and could potentially change the perspective of population health. The sustainability of this level of dead discards is unknown. Based on the abundance of blue sharks in the large pelagic fish catch, it is probable that these estimates of dead discards for blue sharks exceed those of any other large pelagic fish species in the North Atlantic. However, the absence of dead discard estimates for virtually all bycatch species underlines the importance of estimating discard mortality for other fishes.

Acknowledgements. We greatly appreciate the cooperation and assistance of Nova Scotia swordfishermen in this study. We also thank M. Fowler and several anonymous referees for constructive reviews of the manuscript and S. Smith for statistical advice. Funding was provided by the DFO International Governance Fund.

\section{LITERATURE CITED}

Akaike $H$ (1973) Information theory and an extension of the maximum likelihood principle. In: Petran BN, Csaaki F (eds) International Symposium on Information Theory. Accadeemiai Kiadi, Budapest, p 267-281

Bonfil R (1994) Overview of world elasmobranch fisheries. Technical report, FAO, Rome

Borucinska J, Kohler N, Natanson L, Skomal G (2002) Pathology associated with retained fishing hooks in blue sharks, Prionace glauca (L.), with implications for their conservation. J Fish Dis 25:515-521

Brill R, Bushnell P, Schroff S, Seifert R, Galvin M (2008) Effects of anaerobic exercise accompanying catch-andrelease fishing on blood-oxygen affinity of the sandbar shark (Carcharhinus plumbeus, Nardo). J Exp Mar Biol Ecol 354:132-143

Campana S, Marks L, Joyce W, Kohler N (2004) Influence of recreational and commercial fishing on the blue shark (Prionace glauca) population in Atlantic Canadian waters. Canadian Stock Assessment Secretariat Res. Doc. 2004/ 069, Ottawa

> Campana SE, Marks L, Joyce W, Kohler NE (2006) Effects of recreational and commercial fishing on blue sharks (Prionace glauca) in Atlantic Canada, with inferences on the North Atlantic population. Can J Fish Aquat Sci 63: $670-682$

Clarke S (2008) Use of shark fin trade data to estimate historic total shark removals in the Atlantic Ocean. Aquat Living Resour 21:373-381

> Davis MW (2002) Key principles for understanding fish bycatch discard mortality. Can J Fish Aquat Sci 59: $1834-1843$

Diaz GA, Serafy JE (2005) Longline-caught blue shark (Prionace glauca): factors affecting the numbers available for live release. Fish Bull 103:720-724

Domeier ML, Dewar H, Nasby-Lucas N (2003) Mortality rate of striped marlin (Tetrapturus audax) caught with recreational tackle. Mar Freshw Res 54:435-445

Erickson DL, Berkeley SA (2008) Methods to reduce bycatch mortality in longline fisheries. In: Camhi MD, Pikitch EK, Babcock EA (eds) Sharks of the open ocean: biology, fisheries and conservation. Blackwell Publishing, Oxford, p 462-471

- Francis MP, Griggs LH, Baird SJ (2001) Pelagic shark bycatch in the New Zealand tuna longline fishery. Mar Freshw Res 52:165-178

> Gurshin CWD, Szedlmayer ST (2004) Short-term survival and movements of Atlantic sharpnose sharks captured by hook-and-line in the north-east Gulf of Mexico. J Fish Biol 65:973-986

Harrington JM, Myers RA, Rosenberg AA (2005) Wasted fishery resources: discarded by-catch in the USA. Fish Fish $6: 350-361$

Horodysky AZ, Graves JE (2005) Application of pop-up satellite archival tag technology to estimate postrelease survival of white marlin (Tetrapturus albidus) caught on circle and straight-shank (' $\mathrm{J}$ ') hooks in the western North Atlantic recreational fishery. Fish Bull 103:84-96

ICCAT 2008. International Commission for the Conservation of Atlantic Tunas. Report of the 2008 shark stock assessments meeting. ICCAT SCRS/2008/017, Madrid

> Kaplan IC, Cox SP, Kitchell JF (2007) Circle hooks for Pacific longliners: not a panacea for marlin and shark bycatch, but part of the solution. Trans Am Fish Soc 136:392-401

> Kerstetter DW, Graves JE (2006) Effects of circle versus $\mathrm{J}$-style hooks on target and non-target species in a pelagic 
longline fishery. Fish Res 80:239-250

Kerstetter DW, Luckhurst BE, Prince ED, Graves JE (2003) Use of pop-up satellite archival tags to demonstrate survival of blue marlin (Makaira nigricans) released from pelagic longline gear. Fish Bull 101:939-948

Lewison RL, Crowder LB, Read AJ, Freeman SA (2004) Understanding impacts of fisheries bycatch on marine megafauna. Trends Ecol Evol 19:598-604

Mandelman JW, Farrington MA (2007) The estimated shortterm discard mortality of a trawled elasmobranch, the spiny dogfish (Squalus acanthias). Fish Res 83:238-245

Mandelman JW, Cooper PW, Werner TB, Lageux KM (2008) Shark bycatch and depredation in the U.S. Atlantic pelagic longline fishery. Rev Fish Biol Fish 18:427-442

Matsunaga H, Nakano H (2000) Report on information of bycatch fishes obtained from Observer Program for Japanese tuna longline fisheries in the Atlantic Ocean. Col Vol Sci Pap ICCAT 51:1805-1810

Megalofonou P, Damalas D, Yannopoulos C (2005) Composition and abundance of pelagic shark by-catch in the eastern Mediterranean Sea. Cybium 29:135-140

Mejuto J, Garcia-Cortés B, Ramos-Cartelle A, de la Serna JM (2008) Scientific estimations of bycatch landed by the Spanish surface longline fleet targeting swordfish (Xiphias gladius) in the Atlantic Ocean with special reference to the years 2005 and 2006. ICCAT SCRS Doc. 2008/045, Madrid

Moyes CD, Fragoso N, Musyl MK, Brill RW (2006) Predicting postrelease survival in large pelagic fish. Trans Am Fish

Editorial responsibility: Stylianos Somarakis,

Crete, Greece
Soc 135:1389-1397

> Neilson JD, Waiwood KG, Smith SJ (1989) Survival of Atlantic halibut (Hippoglossus hippoglossus) caught by longline and otter trawl gear. Can J Fish Aquat Sci 46:887-897

> Pollock KH, Pine WE III (2007) The design and analysis of field studies to estimate catch-and-release mortality. Fish Manag Ecol 14:123-130

R Development Core Team (2008) R: A language and environment for statistical computing. R Foundation for Statistical Computing, Vienna. www.R-project.org.

> Skomal GB (2007) Evaluating the physiological and physical consequences of capture on post-release survivorship in large pelagic fishes. Fish Manag Ecol 14:81-89

- Stoner AW, Kaimmer SM (2008) Reducing elasmobranch bycatch: laboratory investigation of rare earth metal and magnetic deterrents with spiny dogfish and Pacific halibut. Fish Res 92:162-168

Therneau TM, Grambsch PM (2000) Modeling survival data: extending the Cox model. Springer, New York.

Tsuboi J, Morita K, Ikeda H (2006) Fate of deep-hooked white-spotted charr after cutting the line in a catch-andrelease fishery. Fish Res 79:226-230

Ward P, Myers RA, Blanchard W (2004) Fish lost at sea: the effect of soak time on pelagic longline catches. Fish Bull (Wash DC) 102:179-195

Ward P, Lawrence E, Darbyshire R, Hindmarsh S (2008) Large-scale experiment shows that nylon leaders reduce shark bycatch and benefit pelagic longline fishers. Fish Res 90:100-108

Submitted: February 19, 2009; Accepted: May 14, 2009

Proofs received from author(s): July 20, 2009 